\title{
TO DETERMINE CORRELATION BETWEEN MEAN PERIPHERAL LEUCOCYTE COUNTS AND MEAN LESION VOLUME IN ACUTE ISCHEMIC STROKE
}

\author{
Raees Iqbal Khan, Arshad Mehmood*, Abdul Latif Khattak, Hina Syeda, Raja Jibran**, Irfan Najam Sheen*** \\ Combined Military Hospital Quetta/National University of Medical Sciences (NUMS) Pakistan, *Combined Military Hospital Dera Nawab/ \\ National University of Medical Sciences (NUMS) Pakistan, ${ }^{* *} 123$ Medical Battalion, Tolti/National University of Medical Sciences (NUMS) \\ Pakistan, ${ }^{* * *}$ Combined Military Hospital Malir/National University of Medical Sciences (NUMS) Pakistan,
}

\begin{abstract}
Objective: To determine correlation between mean peripheral leucocyte counts and mean lesion volume in acute ischemic stroke.

Study Design: Cross sectional study.

Place and Duration of Study: We have performed all this research work Combined Military Hospital Quetta, from Jan 2018 to Dec 2018.

Methodology: All admitted patients fulfilling the inclusion criteria were incorporated in the study. The diagnosis of acute ischemic stroke was based on symptoms of focal neurologic insufficiency and MRI brain evidence of infarct. Total peripheral leucocyte counts were calculated under the supervision of a pathologist who is the fellow of CPSP and has addition a 110 years of experience in pathology. All the above stated evidence including name, age, gender and address were documented in the study Performa.

Results: Total no of patients in our study was 70 . Of total patients $39(55.71 \%)$ were male and $31(4.29 \%)$ were females. Correlation between mean peripheral leucocytes counts and mean lesion volume in acute ischemic stroke was calculated as $15.97 \pm 3.53 \times 10^{9}$ for TLC and $12.50 \pm 3.24$ for lesion volume, final results of R are 0.7936 . Positive correlation revealed that both increased. $\mathrm{X}$ variable scores proportionately related with increased $\mathrm{Y}$ variable scores. Same goes for decreased values. The coefficient of determination R2 results turned out to be 0.6298.

Conclusion: We concluded a positive correlation between mean peripheral leucocytes counts and mean lesion volume in acute ischemic stroke. Additional studies are mandatory to validate our findings to establish positive correlation.
\end{abstract}

Keywords: Acute ischemic stroke, Mean peripheral leucocytes counts, Mean lesion volume.

This is an Open Access article distributed under the terms of the Creative Commons Attribution License (http://creativecommons.org/licenses/by/4.0), which permits unrestricted use, distribution, and reproduction in any medium, provided the original work is properly cited.

\section{INTRODUCTION}

Acute stroke has emerged these days as secondary leading cause of death and disability over the world specifically in established and developed countries ${ }^{1,2}$ where per capita in come is high. Stroke leads to more deaths asrelated to cardiovascular diseases in East Asian countries. With the passage of time the occurrence of stroke in developed countries has dropped. As a result of this disease the projected incidence in advanced countries in 2008 was about 94/100,000 population. In comparison to developing countries the frequency is on the rise with estimated incidence of about $117 / 100,000$ population ${ }^{3}$. Pakistan is sixth most populated country in the world. $4.8 \%$

Correspondence: Dr Raees Iqbal Khan, Medical Specialist, Combined Military Hospital, Quetta Pakistan

Received: 31 May 2019; revised received: 01 Jul 2019; accepted: 04 Jul 2019 of country population may be suffering from stroke i.e. 7.2 million as compared to 700,000 in US4. Studies and research work is being done to make swift diagnosis. This work will help to develop healthy life style once stroke has occurred.

Neurological examination is a easy way for making diagnosis. These efforts will help to localize the site of lesion. Magnetic resonance imaging (MRI) brain is the typical early radiogical method in evaluating ischemic stroke. It is helpful especially when done within 24 hours of start of symptoms especially in patients with minor symptoms. Although magnetic resonance imaging (MRI) brain is more sensitive than CT scan in analyzing initial lesions ${ }^{5}$ a number of biologic markers such as C-reactive protiens, D-dimers, total leucocytes counts and MMP-9 are also found to beelevated. These acute phase reactants are not 
only supportive for ordering other diagnostic tests. It will help in establishing acute stroke evolution and prognosis 6 .

Knowledge regarding anterior, middle and posterior cerebral arteries along with circle of will is structures is important. It helps us to locate site of pathology that where lesion is located. This will guide us in choosing the advanced therapies. As advancement of technology and development of MRI in evaluation of acute ischemic stroke diagnos is it is very easy to search for lesion in cerebral artery territory. It helped us in stroke localization. Therefore only history and neurological examination is not enough to localize the lesion. This method has certain limitations ${ }^{7}$. There are 3 factors which contribute to this issue. First, there are developmental differences in anatomy of vessels of brain of different individuals. Second, various pathways tested i.e. corticospinal tracts (which carry motor fibers), spinothalamic tracts (which carrysensoty fibers) pass through different arterial territories between brainstem, basal ganglia, Cortex, and spinal cord. Lastly, Area of ischemic penumbra produces the resultsin which largearterial lesions become similar to smaller lesions. Instead of these complicated lesions large-vessels produce extensive area of ischemia. As a result of these neurologicd efects larger domains of brain become involved. Lacunar syndromes are produced by occlusions of small vessels. Lesions in brain stem result cranial nerve lesions on same side of infarct area along with contralateral neurological deficits. Due to vast knowledge of vessels territories and resultant deficits supported by neuroimaging outcome seem as persistently valuable i.e. lesions incortically basedfunctions and lesions in brainstemlocalizing functions. Cortical functions are cerebralprocesses whoseoutputs are mediated exclusively via certainareas of cerebral cortex. Manyof these functions comes from association cortex. Expressive language is function of posteriorinferior frontal lobe. Posterio-superior temporal lobes controls receptive language function. Lesions in sensory associations cortex resultsin signs related to receptive neurological defects. Among these few signs include i.e. agraphesthesia, astereognosis, apraxia, agnosias, hemiinattention, and few numbers of visual field defects. Precise assessment of cortical functions needs primary modality to be intact ${ }^{8}$.

Leucocytes are blood cellsproduced during adult life in bone marrow tofight against attacking pathogens. These leucocytes act against acute inflammatory injury to body tissues. Recruitment of leucocytes specifically neutrophils may be detected during initial $5 \mathrm{hrs}$ after ischemic stroke establishment. Levels goes at higher limit during first $24 \mathrm{hrs}$. After going extensively through literature total leucocyte counts has been shown to correlate with severity of ischemic stroke. Large volume infarctions are directly related toraised total peripheral leucocytes. Higher values of WBC and ESR were foundin patients with large artery occlusion. All these factors are related to poor prognosisdue to large volume of brain parenchyma. All those who suffered extensive neurologic deterioration after sustaining the stroke were found to have increased leukocyte counts in their peripheral blood 9 .

Developing countries like Pakistan where health care facilities are deficient with CT scans and MRI modalities are non-approachable in few areas. Therefore full blood counts are easily available and cost effective parameter. Main aim of this study is to estimate local correlation between mean peripheral leucocytes counts and infarct volume on MRI scan among patients who suffered acute ischemic stroke. On thebasis of total peripheral leucocyte counts, it can be recommended as routine screening tool for estimation of infarct volume on MRI scan.

\section{METHODOLOGY}

This crosssectional study was carried out in emergency department, Combined Military Hospital Quetta, from January 2018 to December 2018. With the help of WHO recommended calculator for health studies. Sample size was calculated in correlation determination studies with the following assumptions: 
Presumed Correlation between total peripheral leucocytes counts and lesion volume = 0.985 , significance Level $=5 \%$ (0.05) with sample size $n=70$ patients. Sampling method non- used was probability consecutive sampling. Patients with acute ischemic stroke of either gender or age between 30 to 75 years were included in the study. Patients onanticoagulants or with any other known bleeding disorder, with history of recurrent stroke, patients with hemorrhagic stroke, doubt of any disease as pulmonary embolism, Deep vein thrombosis, Sepsis, Or concurrent severe systemic disease that may cause raised total leucocytes counts were excluded from the study.

\section{Data Collectionand Analysis Procedure}

Approval was taken from hospital ethical and research committee to perform this work. Indoor patients fulfilling the inclusion criteria were made part of this study. The diagnosis of acute ischemic stroke was centered on symptoms of focal neurologic deficit and MRI brain evidence of infarct. The aim of study was explained to the patients. Consent was taken on sample performa paper.

All patients were subjected to detailed history and examination. Infarct volume was calculated on MRI brain by using formula as mention above. From all patient 5cc of blood was taken under strict aseptic technique and sent to hospital laboratory on the same day. Total peripheral leucocytes counts were measured under the supervision of a pathologist who is a fellow of CPSP and has more than 10 years of experience in pathology.

Above noted information like name, age, gender and address were written in the study Performa. Exclusion criteria was adopted. All confounders and bias were abolished in study results.

Data was copied in SPSS 17.0. Mean \pm SD was countedfor persistently changing variable like age, infract volume on CT and total peripheral leucocytes counts. Categorical variable is gender were ploted as frequencies and percen- tages. Pearson's correlation coefficient was calculated for bivariate relation ship between total leucocytes counts and infarct volume on MRI. All results were presented as tables and graphs.

The inclusion criteria of this study was both genders, patients aged between 30 to 75 years and patients with acute ischemic stroke. The exclusion criteria were patients on anticoagulants or with any other known bleeding disorder, history ofrecurrent stroke, patients with hemorrhagic stroke and suspicion of any disease as pulmonary embolism, deep vein thrombosis, sepsis, or concurrent severe systemic illness that may cause raised total leucocytes counts

\section{RESULTS}

A total of 70 cases satisfying the inclusion / exclusion criteria were registered to determine correlation between mean peripheral leucocytes counts and mean lesion volume in acute ischemic stroke. Patients were distributed according to age of the patients, it showed that $28(40 \%)$ were between 30-55 years of age, 42 (60\%) were between 56-70 years of age, mean \pm SD was calculated as $57.4 \pm 6.95$ years. Patients were distributed according to gender, 39 (55.71\%) were male and $31(4.29 \%)$ were females (table-II).

Table-I: Age distribution $(\mathrm{n}=70)$.

\begin{tabular}{|c|c|}
\hline Age (Years) & n (\%) \\
\hline $30-55$ & $28(40)$ \\
\hline $56-70$ & $42(60)$ \\
\hline Total & $70(100)$ \\
\hline Mean \pm SD & $57.4 \pm 6.95$ \\
\hline \multicolumn{2}{|c|}{ Table-II: Gender distribution $(n=70)$} \\
\hline Gender & n (\%) \\
\hline Male & $39(55.71)$ \\
\hline Female & $31(44.29)$ \\
\hline Total & $70(100)$ \\
\hline
\end{tabular}

Table-III: Correlation between mean peripheral leucocytes counts and mean lesion volume in acute ischemic stroke $(n=70)$.

\begin{tabular}{l|l}
\hline Correlation & Mean \pm SD \\
\hline TLC $\left(\times 10^{9}\right)$ & $15.97 \pm 3.53$ \\
\hline Lesion volume & $12.50 \pm 3.24$ \\
\hline
\end{tabular}

Correlation between mean peripheral leucocytes counts and mean lesion volume in acute ischemic stroke was calculated as $15.97+3.53 \mathrm{x}$ 
$10^{9}$ for TLC and $12.50 \pm 3.24$ for lesion volume, the value of correiation coefficient is 0.7936 . This is a strong positive correlation, which means that high $\mathrm{X}$ variable scores go with high $\mathrm{Y}$ variable scores (and vice versa). The value of $\mathrm{R} 2$, the coefficient of determination, is 0.6298 .

The value of correlation coefficient is 0.7936 . This is a strong positive correlation, which means that high $\mathrm{X}$ variable scores go with high $\mathrm{Y}$ variable scores (and vice versa).

The value of $\mathrm{R} 2$, the coefficient of determination, is 0.6298 .

\section{DISCUSSION}

Stroke has been declared as most common cause of life long disability. It is the second common reason in etiology of dementia. Stroke is the third most common cause of the death and disabilities especially in the developing world ${ }^{10}$. Lesion volume is considered as an beneficial parameter mimicking the primary pathological condition. Therefore the severity of this neurological deficits relates to neurological findings and functional outcome. Assessment of blood pressure, temperature, respiratory rate, pulse rateand ensuring stability of airway, breathing and circulation is the part of the initial assessment of all patients. All those with grave illness need this initial assessment, including those with stroke ${ }^{11}$. After calculating the time of ischemic stroke symptoms, main goal is to select those patients who will be requiring initial treatment with intravenous thrombolysis. For patients in whom exact time duration of stroke could not be estimated they are not the candidate for thrombolysis. This time of onset of symptoms to the time of presentation at emergency department is defined as the time the patient was last awake and free of stroke symptoms ${ }^{12}$.

We organized this study with the view that in developing countries like Pakistan where health care facilities are limited with neuro-imaging unreachable in certain areas, Full Blood Counts are easily available and cost effective parameter. However, we planned to develop local correlation between mean peripheral leucocytes counts and infarct volume on MRI scan among patients with acute ischemic stroke.

In our study, 28 (40\%) were between 30-55 years of age, $42(60 \%)$ were of age $51-70$ years. Mean \pm SD was counted as $57.4 \pm 6.95$ years. Among these 39 (55.71\%) were male and 31 $(4.29 \%)$ were females, correlation between mean peripheral leucocytes counts and mean lesion volume in acute ischemic stroke was calculated as $15.97 \pm 3.53 \times 10^{9}$ for TLC and $12.50 \pm 3.24$ for lesion volume which showed $\mathrm{R}=0.7936$. This relationship shows that in creased $X$ variable scores proportionately linked with high $\mathrm{Y}$ variable scores. R2, the coefficient of determination value is 0.6298 .

A previous study, reveals median DWI volume on MRI for all ischemic strokes of different etiology were respectively: at admission total leucocytes counts of $0.26-0.97 \times 10^{9} / \mathrm{L}$ in those with $0.38 \mathrm{ml}$ infarctions, $1.98-35.17 \times 10^{9} / \mathrm{L}$ in $7.24 \mathrm{ml}$ infarctions, $1.19-12.51 \times 10^{9} / \mathrm{L}$ in $5.12 \mathrm{ml}$ infarctions, $1.22-63.24 \times 10^{9} / \mathrm{L}$ in $15.86 \mathrm{ml}$ in farctions and $0.62-51.37 \times 10^{9} / \mathrm{L}$ in $10.84 \mathrm{ml}$ in farctions size ${ }^{13}$. A positive correlation established during calculation of lesion volumes as correlation coefficient of $0.985^{13}$. Results in this study are positive.

In other research work $^{14}$, prevalence of TOAST stroke subtypes variedamong leukocyte quartiles and peripheral neutrophil $(p<0.001)$. There for elymphocyte quartiles remained static. The values of some of patients were expressed as percentages who were having small vessel, cardio-embolic within each leukocyte and peripheral neutrophil count. Among different strokes subtypes a pair wise values were compared in between leukocyte and neutrophil quartiles. Half of strokes were declared as small vessel obstructive stroke in the lowest leukocyte quartile. This has a higher proportion as compared to three higher leukocyte quartiles $(19 \%, 23 \%$ and $9 \%$, respectively; $p<0.05)$. Pathology of cardio-embolic and large vessel strokes did not vary among leukocyte quartiles. The proportionate values of small vessel obstruction was higher among neutrophil 
quartiles at lower valuesas compared the highest quartile values $(43 \%$ versus $8 \%, p<0.05)$. Rest of results were not significant.

Univariate and adjusted multivariate analyses were applied to all quartile of total leukocyte count, neutrophil count, and lymphocyte count. Both DWI volume was positively correlated with total leukocytes (Spearman rho=0.371, $p<0.001$ ). Also positively in creasing values were noted for neutrophils counts (Spearman rho $=0.415$, $p<0.001)$. Lymphocytes counts did not showed positively increasing values. Asleukocyte quartiles values increased, the value of DWI lesion volumes also increased. All these values were found on performing bivariate median regression analysis. Patients with high ermedian lesion volumes had appropriately more levels of leukocyte quartile as compared to lower 3 quartiles. Lower three quartiles did not varied significantly. Neutrophil and lymphocyte counts increased with in creasing size of DWI lesion volume. Neutrophil counts and total leukocyte counts showed equal results. Highest quartile volumes results were significantas compared to lower three quartiles. Little variations were noted in DWI volume values for lower thre eperipheral neutrophil counts values. In creasing trend for the lymphocyte count was not similar to neu-trophil counts. It showed in creased DWI lesion volume in the second quartile.

Results of multivariate values of total leukocyte and peripheral neutrophilia with DWI lesion volumes were identical to the bivariate analysis. In creasing DWIl esion volumes showed rising trend in levels of leukocyte and neutrophil count. Variability in DWI volumes falling in the highest neutrophil quartile was consider ably high as compared to lower 3 quartiles $(p<0.001)^{14}$ on performing pair wise comparison. However, on the basis of total peripheral leucocyte counts, we can recommend TLC as routine screening tool for estimation of infarct volume on MRI scan.

\section{CONCLUSION}

We concluded a positive correlation between mean peripheral leucocyte counts and mean lesion volume in acute ischemic stroke. Some others tudies are needed to validate our findings.

\section{ACKNOWLEDGMENT}

We acknowledge every patients and volunteers who participated in this study.

\section{CONFLICT OF INTEREST}

This study has no conflict of interest to be declared by any author.

\section{REFERENCES}

1. Huo Y, Li J, Qin X, Huang Y, Wang X, Gottesman RF, Tang G, Wang B, Chen D, He M, Fu J. Efficacy of folic acid therapy in primary prevention of stroke among adults with hypertension in China: the CSPPT randomized clinical trial. J Am Med Assoc 2015; 313(13): 1325-35.

2. Smajlović D. Strokes in young adults: epidemiology and prevention. Vasc Health Risk Manag 2015; 11(1): 157-64.

3. Suwanwela NC. Stroke epidemiology in Thailand. J Stroke 2014; 16(1): 1-5.

4. Kumar AD, Boehme AK, Siegler JE, Gillette M, Albright KC, Martinschilds. Leukocytosis in patients with neurologic deterio-ration after acute ischemic stroke is associated with poor out-comes. J Stroke Cerebrovascular Dis 2013; 22(7): e111-17.

5. Nikanfar M, Shaafi S, Hashemilar M, Oskarii DS, Goldust M. Evaluating role of leukocytosis and high sedimentation rate as prognostic factors in acute ischemic cerebral strokes. Pak J Biol Sci 2012; 15(8): 386-90.

6. Mittal SH, Goel D, Choudhary S, Chowdhury D, Mishra TK, Agarwal S. Mortality in ischemic stroke score: A predictive score of mortality for acute ische. Temporal profile of serum levels of il-6 in acute ischemic stroke and its relationship with stroke severity and outcome in indian population. Int J Intg Med Sci 2018; 5(1): 555-60.

7. Mozaffarian D, Benjamin EJ, Go AS, Arnett DK, Blaha MJ. Heart disease and stroke statistics--2015 update: a report from the American Heart Association. Circulation 2015; 131(4): e29-322.

8. Ovbiagele B, Goldstein LB, Higashida RT, Howard VJ, Johnston SC, Khavjou OA. Forecasting the future of stroke in the United States: a policy statement from the american heart association and american stroke association. Stroke 2013; 44(8): 2361-75.

9. Gill D, Sivakumaran P, Aravind A, Tank A, Dosh R, Veltkamp R. Temporal trends in the levels of peripherally circulating leukocyte subtypes in the hours after ischemic stroke. J Stroke Cerebrovascular Dis 2018; 27(1): 198-202.

10. O'Donnell MJ, Chin SL, Rangarajan S, Xavier D, Liu L, Zhang H, et al. Global and regional effects of potentially modifiable risk factors associated with acute stroke in 32 countries (interstroke): a casecontrol study. Lancet 2016; 388(10046): 761-75.

11. Hemphill JC, Greenberg SM, Anderson CS. Guidelines for the management of spontaneous intracerebral hemorrhage: a guide-line for healthcare professionals from the american heart association/american stroke association. Stroke 2015; 46(1): 2032.

12. Jauch EC, Saver JL, Adams HP. Guidelines for the early management of patients with acute ischemic stroke: a guideline for healthcare professionals from the american heart association/ american stroke association. Stroke 2013; 44(3): 870-947.

13. Montaner J, Perea-Gainza M, Delgado P, Ribó M, Chacón P, Rosell A, et al. Etiologic diagnosis of ischemic stroke subtypes with plasma biomarkers. Stroke 2008; 39(8): 2280-87.

14. Buck BH, Liebeskind DS, Saver JL, Bang OY, Yun SW, Starkman S. Early neutrophilia is associated with volume of ischemic tissue in acute stroke. Stoke 2008; 39(2): 355-60. 
